Folia Histórica del Nordeste, $\mathbf{N}^{\circ} 19$ (Resistencia, 2011) IIGHI, IH - CONICET, UNNE

\title{
PROBLEMAS SOCIALES CONVERTIDOS EN PROBLEMAS AMBIENTALES: TRES CASOS PARADIGMÁTICOS EN EL AGRO DE MISIONES, ARGENTINA
}

\author{
Social Problems Turned into Environmental Problems: Three Paradigmatic Cases in \\ the Agrarian Zone of Misiones, Argentina
}

Brian Ferrero y Carla De Micco

\section{Resumen}

En el contexto del nuevo paradigma participativo de conservación, el ambientalismo se está tornando un campo desde donde se construye territorialidad, que conlleva una nueva forma de institucionalizar el territorio y manejarlo tanto por parte del Estado, como por agencias no gubernamentales ambientalistas y de desarrollo. En tal proceso, el ambientalismo se presenta como un medio eficaz de resolver conflictos sociales y territoriales. Aquí, es central el despliegue de un aparato institucional ambientalista que implica la presencia de nuevos actores, proyectos y discursos, y la redefinición de los que ya se encontraban presentes. En este trabajo analizaremos tres casos paradigmáticos en el agro de Misiones, Argentina.

$<$ Ambientalismo $><$ conflicto social $><$ conflicto territorial $><$ Misiones $>$

\begin{abstract}
Within the context of the new participative paradigm of conservation, the environmentalism is becoming a field from where territoriality is constructed. This paradigm implies a new way for the territory to become institutionalized, and to be handled by the State and by environmental and developmental nongovernmental agencies. In such process, the environmentalism appears as an effective way of solving social and territorial conflicts. Hence, the deployment of an environmentalist institutional device that implies the presence of new actors, projects and speeches, and the redefinition of those who already were present, is central. In this paper we will analyze three paradigmatic cases in the agro of Misiones, Argentina.
\end{abstract}

$<$ Ambientalism $><$ Social conflict $><$ Territorial conflict $><$ Misiones $>$ 


\section{Introducción}

En el año 2002 comunidades mbya-guaraní que habitan tierras en propiedad de empresas forestales, dentro de la Reserva de Biosfera Yabotí (en la provincia de Misiones) inician reclamos para que se detenga la explotación de los montes nativos en torno a sus aldeas. A partir de la intervención de una ONG local y del Equipo Nacional de la Pastoral Indígena, el reclamo adquiere difusión pública, llega a ser tratado en el Congreso Nacional y pasa a ocupar un lugar destacado en la agenda política de la provincia. En la búsqueda de una resolución se convocó a diversos sectores sociales, tales como el Estado provincial y el nacional, universidades, propietarios de tierras, ONGs ambientalistas y de desarrollo, la iglesia católica local, y representantes de las comunidades mbya-guaraní, creándose un ámbito de debates y discusiones. En 2006 se resolvió inhibir la explotación forestal de 10 mil hectáreas que se encuentran dentro de la Reserva, habitadas por las comunidades mbya-guaraní, pero en propiedad de dos empresas; con esta medida por primera vez en un siglo se buscó beneficiar a las comunidades indígenas sobre las empresas forestales.

Ese mismo año, en 2006, un conjunto de pequeños productores de colonia Primavera, vecina a la Reserva, ocuparon tierras privadas que se encuentran en el interior de ésta. Alegaron que necesitaban tierras para ampliar sus áreas de cultivo, pero cuando se presentaron las autoridades de la Reserva, los pobladores aprovecharon para hacer otros reclamos referidos a las condiciones de vida en la colonia. Estas autoridades crearon una mesa de diálogo con los vecinos, y consiguieron que desocupen esas tierras a cambio de implementar proyectos de desarrollo agrícola.

Estos dos conflictos fueron resueltos de una forma innovadora en Argentina, pero que gradualmente se está expandiendo, de resolver conflictos sociales en áreas afectadas o vecinas a Reservas Naturales. Una de las funcionarias de la Reserva lo expresa claramente: "había dos caminos para resolver los conflictos, uno corto y fácil y otro más largo y comprometido". En esta lógica, en el primer caso, el camino corto hubiese consistido en no dar lugar a los reclamos indígenas, o hacerlos naufragar en un mar de vaivenes burocráticos. En el segundo caso consistiría en que el gobierno provincial, con el respaldo de un juez penal, aplicase la ley para desalojar a los intrusos y penalizarlos. A su vez esto podría haber servido para mostrar la necesidad de incorporar mayor número de guarda parques a la Reserva para cumplir tareas de control y fiscalización. Según la misma funcionaria "por ese camino (corto, que ha sido el habitual en la región) se resolvía el conflicto pero no el ambiental o de fondo". En cambio se eligió "el camino más largo: instaurar el diálogo y la participación, ver los temas de fondo que originan los conflictos y trabajarlos de manera integral" (Palma; 2008:26).

Estos casos marcan una diferencia sustancial con el paradigma conservacionista que predominó en el país hasta inicios del siglo XXI, basado en el control, la sanción, y separación de las poblaciones locales del ambiente por conservar. En cambio, la nueva modalidad de conservación, denominada "enfoque eco sistémico" o "paradigma 
participativo", apunta al desarrollo de las comunidades, otorgándoles poder de decisión, e implica una nueva forma en que se institucionalizan territorios marginales. En estos territorios, como en el caso del norte de Misiones, si bien históricamente el Estado ha tenido una escasa presencia, a principios del siglo XXI, comienza a intervenir en la regulación del espacio y las poblaciones junto a agencias no gubernamentales de desarrollo y conservación, movimientos sociales y las "poblaciones locales". En este proceso, los problemas sociales de indígenas y pequeños productores rurales (relacionados al acceso a los recursos naturales, necesidades de tierras, mejoras en las condiciones de comercialización de los productos agrícolas, acceso a servicios públicos, caminos, escuelas, e incluso la "pobreza") comienzan a ser abordados por actores interesados en la conservación del ambiente, y pasan a ser considerados como "problemas ambientales". De manera que se produce una adquisición de carácter ambiental de los problemas sociales y de las políticas públicas.

Este proceso se presenta como una nueva forma de gobierno de los territorios y las poblaciones. La modernidad capitalista requirió del desarrollo de formas de gobierno sobre recursos y poblaciones basado en el conocimiento de expertos planificadores, estadistas, economistas y demógrafos, lo que Foucault (1991) ha denominado "gobernabilidad". La gobernabilidad, desde esta perspectiva, es un fenómeno moderno fundamental por medio del cual vastos ámbitos de la vida cotidiana fueron apropiados, procesados y transformados de manera creciente por el conocimiento experto y los aparatos administrativos del Estado. Esto se ha extendido al orden natural a partir del manejo científico de los bosques y la agricultura de plantaciones hasta la gestión del desarrollo sostenible. De manera que proponemos analizar estas modalidades de participación de las comunidades locales en la gestión del espacio, como parte del proceso de gobierno de la naturaleza, el territorio y la población, por los aparatos del Estado y del conocimiento, es decir, hecha objeto del conocimiento experto, regulada, simplificada, disciplinada, administrada, planificada ${ }^{1}$.

En este trabajo investigaremos la implementación de este paradigma ambientalista que pretende integrar a las poblaciones locales a la conservación del ambiente, creando espacios de diálogo, y otorgándoles algunas cuotas de poder en la toma de decisiones, o "empoderándolas" según el término nativo. Estudiaremos tres casos en la provincia de Misiones, en el norte argentino. Por un lado los dos casos ya mencionados, el de las negociaciones por el acceso a tierras privadas para comunidades mbya-guaraní, y la aplicación de proyectos de desarrollo y conservación en los límites

\footnotetext{
${ }^{1}$ Estas consideraciones parten de la perspectiva de Foucault (1988), para quien el poder organiza las posiciones y opera al interior de éstas. La noción de poder que maneja Foucault se basa en la habilidad para estructurar el posible campo de acción de los otros; esto es gobernar en el sentido del ejercicio de "la acción sobre la acción". Eric Wolf (1990), a su vez, define a este tipo de poder que se genera en esta forma de acción como "poder estructural", en base a lo cual redefine la noción de "relaciones sociales de producción" y enfatiza el poder para organizar y localizar el trabajo social. De manera que para Wolf, al pensar el poder primeramente en términos interaccionales, las relaciones de gobierno no son visibles, sino que el poder estructural forma el campo de acción social de modo de hacer cierto tipo de comportamiento posible, mientras otros se hacen menos posibles o imposibles.
} 
de la Reserva. El tercer caso es el de implementación de proyectos de desarrollo rural en el área de influencia del Parque Nacional Iguazú (PNI, en el norte de Misiones) a través de instituciones ambientalistas. Tales proyectos constituyen la primera relación formal y sistemática entre el Parque y los pobladores del área de influencia luego de 80 años de haber sido creado. Los proyectos son implementados por la administración del Parque con participación de Agencias de Cooperación Internacional de los gobiernos de España y Japón, y apuntan a revertir la situación de pobreza de los productores. En concreto se están creando cooperativas agrícolas y circuitos de agroturismo, se realizan campañas de educación ambiental para disminuir el desmonte y caza de fauna silvestre. Pero en la investigación que proponemos no sólo se aborda la implementación del nuevo paradigma, sino también las formas en que los pobladores locales lo aprovechan, manipulan, y transforman de acuerdo a sus intereses y posibilidades. Lo significativo de la situación actual es que son organizaciones ambientalistas quienes se hacen cargo de los conflictos sociales, encabezadas por el Estado; a su vez los pobladores aceptan como legítimo tal cauce para sus reclamos. Cabe destacar el caso de las ONGs inicialmente portadoras de programas desarrollistas, que durante la década del 1990 han ido adoptando perspectivas ambientalistas en su accionar, lo cual señala que las intervenciones en el área rural adquieren nueva legitimidad adoptando el discurso ambientalista.

\section{Contexto regional}

La provincia de Misiones es un espacio privilegiado para estudiar la implementación del nuevo paradigma conservacionista, puesto que desde la década de 1980 es valorada internacionalmente por contener el último remanente continuo de selva paranaense. Esta selva ocupaba toda la mitad este de Paraguay, y el sur de Brasil hasta las costas del Atlántico. En la primera década del siglo XXI se conserva tan sólo el 7\% de la masa boscosa que existía a inicios del siglo XX, del cual $20 \%$ está en Misiones, y el resto se presenta de manera dispersa por toda la región (Di Bitetti et. al.; 2003).

En una primera etapa, las políticas de conservación de la selva se basaron en la creación de Áreas Naturales Protegidas estrictas, que no permitían la presencia de poblaciones en el interior de las mismas. Entre los años 1988 y 2004 se pasó de 6 a 68 Áreas Naturales Protegidas, mientras que la superficie bajo conservación pasó del 2,9\% de la superficie provincial al $26 \%$.

Hacia la década de 1990, tiene lugar una transformación en las políticas conservacionistas. Se comienza a integrar a las poblaciones rurales e indígenas a los proyectos de conservación, cobran peso ideas como las de empoderamiento de la sociedad civil, participación, equidad, transformación en las relaciones de género, y se comienzan a tejer alianzas entre instituciones oficiales y no gubernamentales, tanto conservacionistas como de desarrollo. 


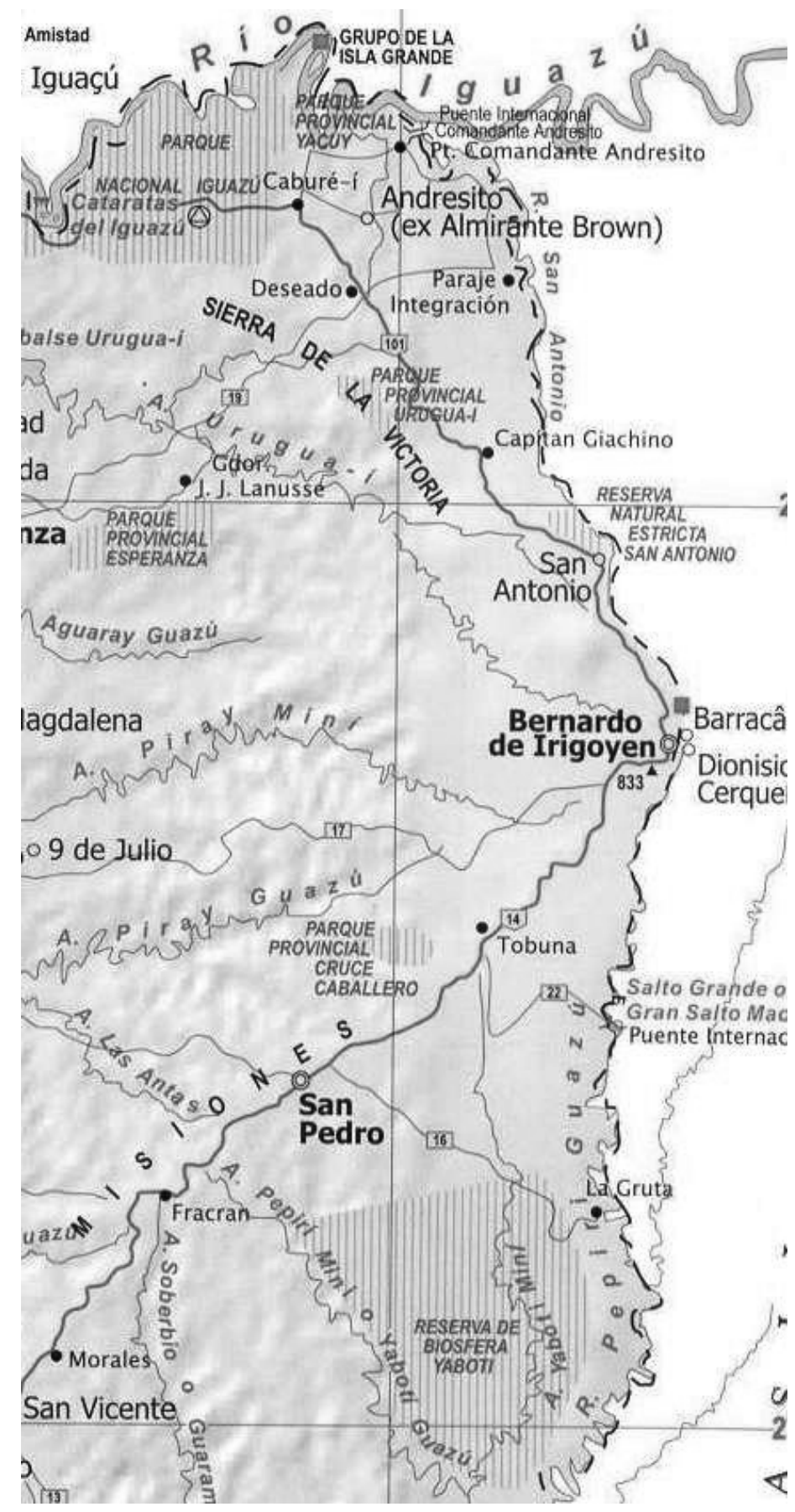

Se hacen presentes agencias conservacionistas estatales provinciales (Ministerio Ecología) y nacionales (Administración de Parques Nacionales, y el Programa que 
regula las Reservas de Biosfera), también agencias no gubernamentales nacionales (Fundación Vida Silvestre Argentina, Conservación Argentina), e internacionales (de Francia, Reino Unido, España, Japón, y la WWF). A esto se suman las agencias de desarrollo que ya venían implementando propuestas de desarrollo sustentable desde inicios de los años ' 90 , y gradualmente van integrándose a redes institucionales con agencias conservacionistas, tal es el caso por ejemplo de INDES, UTR, APHIDAL (previamente el Proyecto Rural de la Pastoral de Iguazú).

En el espacio misionero se despliega un nuevo aparato institucional que crea un territorio ambientalista que pretende integrar a las "poblaciones locales". Estas dejan de ser consideradas como "enemigas de la naturaleza" y pasan a ser valoradas por ciertas "cualidades" como las de tener un mayor contacto con lo natural, posibilidades de producir alimentos sin uso de agroquímicos, contar y reproducir conocimientos sobre el ambiente local y su manejo. La eficacia de esta nueva gobernabilidad se da otorgándole una nueva identidad al territorio, como espacio "natural", y a sus pobladores como "locales" y portadores de la potencialidad de vivir en "equilibrio con la naturaleza".

\section{Transformaciones en el modelo de conservación de la naturaleza}

La vinculación de las poblaciones locales en la gestión de Áreas Protegidas tiene lugar en el marco de una transformación de modelo conservacionista que se inicia en las últimas décadas del siglo XX y que en Argentina recién se está afianzando ya transcurrida la primera década del siglo XXI. El modelo de Áreas Protegidas que ha predominando durante la mayor parte del siglo XX se basó en considerar que existe algo denominado "naturaleza" que es cualitativamente diferente a lo social, y por lo tanto para ser conservado debe ser separado de las poblaciones humanas. El modelo de conservación, que se inicia con la creación del Parque Nacional Yellowstone en Estados Unidos en 1872, implica un control estatal estricto de las áreas, donde los usos humanos del medio natural están completamente prohibidos. En muchos países del tercer mundo, históricamente la implementación de Áreas Protegidas estuvo ligada a proyectos coloniales de conservación en contra de los usos locales, y destinadas al uso colonial para forestación y caza. Pero desde la emergencia de los estados nacionales, las Áreas Protegidas devinieron una forma no sólo de conservar, sino también de manifestar el control del estado sobre el espacio dentro del territorio nacional (Neuman; 1998).

En el paradigma participativo se amplía el área de trabajo, ya no sólo se trabaja sobre las comunidades de flora y fauna sino también las humanas. El trabajo deja de concentrarse dentro de las Áreas Protegidas sino que se desarrolla hacia las comunidades que viven por fuera de éstas.

Como las poblaciones previamente fueron consideradas un factor de presión sobre las Áreas Protegidas, se han generado múltiples conflictos entre éstas y las autoridades de conservación, llevando a la necesidad de fortalecer las funciones de fiscalización y control de las Áreas. El nuevo paradigma considera que las poblaciones locales deben ser socias en la conservación, para esto se busca empoderarlas en la 
toma de decisiones a nivel local, fortalecer su organización social, poner en valor los conocimientos tradicionales sobre el uso de los recursos naturales. Es decir, implica una "aproximación comunitaria, desde abajo, o participativa, basada en la experiencia de que las aproximaciones desde arriba, intervencionista o anti-populares de implementación y manejo de las Áreas Protegidas implica demasiados obstáculos y no ha contribuido a la conservación. Aún más, son demasiado costosas e ineficientes" (Galvin \& Haller; 2008: 20)

Esto paradigma se produce en un contexto de retracción del Estado, que si bien sigue siendo el actor principal en la gestión de las Áreas Protegidas, incluye en el manejo de éstas a movimientos sociales, organizaciones no gubernamentales, agencias financiadoras internacionales, que en muchos casos son quienes aportan los fondos y sugieren las principales líneas de acción.

La transformación del paradigma conservacionista tiene lugar en el marco de una gradual transformación general del tratamiento de lo social por parte de programas de desarrollo y políticas públicas. En los programas de los organismos internacionales que financian proyectos de desarrollo, cada vez cobra mayor relieve la sociedad civil y el concepto de empoderamiento. Tal como sostiene Murillo (2008) la sociedad civil ya no es tratada como cosa sino como multiplicidad de relaciones en red que podrían expresarse y exigir transparencia por intermedio de organizaciones de base y ONGs. Así por ejemplo el Banco Mundial sostiene la necesidad de conformar un nuevo pacto social que requiere un nuevo lugar de la sociedad civil. "Su táctica ha variado -particularmente luego de Seattle, en diciembre de 1999-y ya no radica en imponer sino en re significar el discurso de quienes se oponen a su estrategia; de ese modo, los objetivos propios son presentados en el lenguaje de los dominados" (Murillo 2008:114). De manera que la redefinición de la relación Estado-sociedad civil en las practicas concretas cuenta con al menos tres nuevas aristas: "una mayor injerencia de las grandes empresas en la vida pública y privada, así como en la formación de organizaciones de la sociedad civil; un abandono de los sujetos a la propia iniciativa y el incentivo a construir nuevos lazos de afinidad basados en el género o la etnia, a diferencia de los viejos lazos sindicales o de clase". (Murillo 2008:119).

\section{Caso 1. Comunidades mbya-guaraníes y conflicto por la tierra}

Las comunidades mbya-guaraní viven dentro de la Reserva de Biosfera Yabotí bajo distintas formas de propiedad de la tierra: en algunos casos están en tierras privadas pertenecientes a empresarios forestales, en otros casos en tierras públicas como el Parque Provincial Esmeralda. De las 240.000 hectáreas que tiene la Reserva, el 80 \% de las tierras son de propiedad privada, encontrándose en manos de 32 propietarios que hacen explotación del monte nativo. El resto de las tierras son Parques Provinciales y propiedades de organismos estatales. Previamente a la ocupación de estas tierras por el Estado y por propietarios privados, en la región ya vivían comunidades mbya-guaraní, desarrollando una economía basada en la caza, recolección y horticultura de tala y quema, que implicaba una periódica movilidad territorial. 
Las comunidades mbya-guaraní de la región vienen sosteniendo reclamos históricos sobre la sobre explotación de la selva en que viven, contando con el apoyo del Equipo Nacional de Pastoral Aborigen. Este equipo asesora legalmente a las comunidades desde la década de 1990. Recién a inicios de la década de 2000 se logra que estos reclamos comiencen a tener trascendencia, en particular cuando se hace eco de éstos la ONG ambientalista nacional FUNAM, y sobre todo por cambios en los paradigmas desde los que se abordan los problemas sociales. Esta ONG comenzó una campaña para que se detenga la explotación forestal y los contactos internacionales con que contaba permitieron una rápida repercusión del tema que llegó a ser expuesto en el Congreso Nacional. A su vez, el Comité nacional que regula el manejo de las Reservas de Biosfera argentinas, solicitó al gobierno de la provincia la resolución del problema, enfatizando que debía hacerse con la participación efectiva de todos los actores involucrados.

De aquí en más se conformó una mesa de diálogo, donde participaron el Ministerio de Ecología, representando al Estado provincial, asociaciones forestales, ONGs (FUNAM), la Universidad, los apoderados de las propiedades y los representantes de las comunidades mbya. Si bien en la órbita del gobierno provincial existe una Dirección de Asuntos Indígenas, que legalmente tendría que participar en este tipo de conflictos, los actores mencionados decidieron que esa oficina fuese marginada del proceso. Por un lado, considerando que el tipo de relación que esta Dirección, en general, establece con las comunidades indígenas es de corte clientelar, con lo cual no se llegaría a una resolución efectiva del problema, quedando este solapado bajo escasas prebendas que dividirían a las comunidades. No deja de ser significativo que, existiendo una institución estatal específicamente encargada de administrar dichos conflictos, se cree una institución paralela, que obtiene su legitimación al ser apoyada por organizaciones de corte ambientalista de la sociedad civil.

La mesa de diálogo solicitó, en el 2004, que se realizara un estudio del impacto producido por la actividad forestal en el área de la Reserva donde viven comunidades guaraníes. El estudio, que llevó a cabo la Facultad de Ciencias Forestales, determinó que la explotación maderera estaba ocasionando un impacto negativo sobre cinco aldeas mbya-guaraní. En 2005 un grupo de técnicos y expertos académicos y de ONGs convocados por el Estado provincial, evalúan la situación y concluyen que el criterio básico a subyacer en cada decisión tiene que "ser la defensa y la preservación del patrimonio - tanto presente como pasado, así como los derechos de las comunidades mbya-guaraní que residen en el área. Este criterio fundamental debe prevalecer sobre otros que den prioridad a determinados valores biológicos particulares en juego o la actividad comercial de los empresarios que explotan los lotes involucrados"2. De esta manera se sentó un precedente sobre la forma de resolver conflictos sociales en la región, que llevará a los reclamos de las comunidades mbya-guaraní cuenten con

\footnotetext{
${ }^{2}$ Cita del "Informe de actividades de la Amirby 2005-2006". El equipo que trabajó en este caso estuvo formado por miembros del Ministerio de Ecología, de la ONG Fundación Vida Silvestre Argentina, Facultad de Ciencias Forestales, y CONICET
} 
respaldo, generando más tarde conflictos dentro del Comité de Gestión de la Reservas donde participan empresarios forestales.

En el año 2005, a partir de las consideraciones de la mesa de diálogo, se inhibió la explotación forestal de 10.000 hectáreas de propiedad privada con un alto nivel de degradación y que eran utilizadas por las comunidades mbya-guaraní para caza y recolección. Un año más tarde, se produjo una transformación de la estructura institucional y de funcionamiento de la Reserva y se creó la AMIRBY (Área de Manejo Integral de la Reserva de Biosfera Yabotí, organismo dependiente del Ministerio provincial de Ecología). Conjuntamente se creó un Comité de Gestión del que participan diversos sectores involucrados con la Reserva. Entre estos, los sectores que participan en las reuniones son los funcionarios de la AMIRBY, los propietarios de tierras dentro de la Reserva, las comunidades mbya-guaraní, representantes de colonias del área de influencia, organizaciones no gubernamentales ambientalistas, el equipo nacional de la pastoral aborigen, representantes de los gobiernos municipales donde está la Reserva.

La AMIRBY se presenta como una oficina alternativa dentro del Ministerio de Ecología, puesto que en esta repartición se conformó un equipo enfoca su trabajo a la creación de espacios de participación, y en ofrecer a los sectores desfavorecidos, herramientas para reclamar por sus intereses. En una reunión donde propietarios de tierras dentro de la Reserva reclamaban disminuir los beneficios dados a las comunidades indígenas, el Coordinador de la AMIRBY, señala que "siempre debemos estar del lado de los más desfavorecidos". En general la AMIRBY es vista por quienes trabajan en otras áreas naturales protegidas provinciales como demasiado favorable a los intereses de los pobladores locales, y por tanto desatendiendo las funciones de sanción y control consideradas como centrales en toda área protegida. Frente a las tensiones dentro del Estado que crea el trabajo de la AMIRBY, sus funcionarios han necesitado generar lazos con otras instituciones que trabajan con una visión similar sobre las poblaciones humanas; por ejemplo con el Equipo Nacional de la Pastoral Aborigen, ONGs de desarrollo y ONGs ambientalistas.

\section{Caso 2. La ocupación de tierras privadas por la comunidad de Primavera}

A fines de 2006, llegan rumores a la Colonia Primavera (lindante con la Reserva de Biosfera Yabotí), sobre la futura explotación forestal total de un lote dentro de la Reserva, y su posterior ocupación por productores rurales. Por lo que un grupo de vecinos de la colonia ingresan a dicho lote, manifestando necesidad de tierras para la expansión de sus familias. Eran 62 familias que comenzaron a abrir rumbos, delimitar chacras haciendo campamentos precarios (Palma 2008:11). Un trabajador de este lote dio aviso a miembros del cuerpo de guarda parques, quienes comunicaron la situación a las autoridades del ministerio de ecología y al propietario del lote (poblador de San Pedro). Un vecino que participó de la ocupación manifiesta a los guarda parques que "Nosotros fuimos con el objetivo de tener una chacra, ocupar un pedazo de tierra, para el sustento de nuestros hijos, para tener donde plantar, porque no tenemos tierras 
y queremos un pedazo para plantar, pensamos en el futuro de nuestros hijos ya que no podemos mandarlos a estudiar" (En Palma 2008:12). La última semana del año las autoridades del ministerio se hicieron presentes en el lugar. Un numeroso grupo de vecinos los estaba esperando en el portón de acceso al lote, manifestando que no permitirían que personas de otras colonias ocupasen el lote: si éste debía ser ocupado, sería por la gente del lugar.

En tipo de casos, quién habitualmente actuaba era la policía provincial y la delegación de tierras, pero aquí se hizo cargo de la situación el Ministerio de Ecología. Según relata una funcionaria de la AMIRBY "Primero se les explicó (a los vecinos) el ilícito y gravedad del daño que estaban ocasionando y propusieron como condición para arribar a una solución, el desalojo voluntario del lote por parte de los ocupantes y estos a su vez no recibirían sanciones. El grupo de ocupantes expresó claramente su intención de entablar el diálogo con las autoridades a fin de presentar las necesidades y urgencias por parte de la colonia" (Palma 2008:12). Posteriormente los vecinos de la colonia tuvieron una serie de reuniones con el ministro de Ecología, que luego se prolongarían con funcionarios de la AMIRBY, donde plantearon sus necesidades, en particular de más tierras para dar a los hijos que comienzan a emanciparse.

Para resolver este problema las autoridades provinciales propusieron que se conformase una Mesa de Diálogo en la que participasen el Ministerio de Ecología, los propietarios de tierras dentro de la Reserva y los pobladores que habían ocupado tierras. Para esto se solicitó a los últimos que se organizasen conformando un grupo que contase con una comisión directiva representativa del conjunto de los vecinos.

La Mesa de Diálogo, como instancia de establecimiento de gobernabilidad en la región, implicó una serie de negociaciones entre colonos y Estado. Los aspectos fundamentales acordados fueron: por parte del Grupo Esperanza "No reincidir la acción de intrusión en el predio". Por parte del Estado consistieron en diversos beneficios, por ejemplo la donación de insignias patrias, útiles escolares, guardapolvos y zapatillas a las escuelas de la colonia, también la realización de talleres y cursos para los pobladores destinados a una futura conformación de una cooperativa productiva en la colonia. Por otro lado, se ofreció ayuda para la regularización de DNI de los pobladores locales.

En el proceso de intervención territorial, la AMIRBY realizó una encuesta de las necesidades de la población, que se justificó en tanto la intervención estatal previa en el área, habría sido sorda a la voz de los pobladores; para superar esto los funcionarios estatales consideraron necesario darles la palabra y escucharlos.

Como parte de este proceso, en agosto de 2007 se conformó una Cooperativa Agrícola que lleva por nombre "Colonia Primavera", cuyo presidente es una de las personas que lideraron la ocupación de tierras privadas dentro de la Reserva; mientras el secretario es un miembro del cuerpo provincial de guarda parques. En el año 2008, se logra que una ONG española (Petjades) financie proyectos de desarrollo, consistentes en la construcción de escuelas y programas de producción agrícola sustentable.

En este proceso, los pobladores, en particular quienes participan de la Mesa de Diálogo, pasan a apropiarse de un discurso ambientalista. Podemos decir que quienes 
no participan de tal discurso, quedan por fuera de las negociaciones con el Estado y las ONGs. De manera que el ambientalismo integra a los pobladores y a la colonia a una nueva configuración del desarrollo. Pobladores que se veían marginados del desarrollo pasan a participar, en cierta forma, de la órbita del Estado y de las agencias ambientalistas. Entonces, la agencia estatal (AMIRBY) y las ONGs ambientalistas (Fundación Vida Silvestre, Petjades), que participan en la resolución del conflicto y luego presentan las alternativas de desarrollo, son las que "proponen" los términos de este desarrollo y de cómo han de resolverse los problemas.

\section{Caso 3. El proyecto Araucaria XXI y el desarrollo rural}

A principios del 2008 comienza a implementarse en Misiones un programa asociado a la conservación de las áreas protegidas de la provincia, y que constituye una nueva forma de intervención en la región. El proyecto regional Araucaria XXI Bosque Atlántico es un plan de cooperación internacional para el desarrollo, integrado por los gobiernos de España, Argentina, Brasil y Paraguay. Este proyecto es implementado en conjunto por la AECI (Agencia Española de Cooperación Internacional), la Administración de Parques Nacionales y el Ministerio provincial de Ecología.

"El objetivo principal es contribuir a mejorar la calidad de vida de las poblaciones locales, ubicadas en el Bosque Atlántico del Alto Paraná, a través de la conservación del patrimonio natural y cultural, y de la gestión sostenible de los recursos naturales que ofrece la región. El nacimiento de Araucaria pretende ser un medio para facilitar la comunicación entre todas aquellas personas e instituciones interesadas en la problemática ambiental y social del territorio. También aspira a ser un espacio para el intercambio de información y experiencia entre los distintos actores involucrados en la implementación de las acciones, que se ejecutan en el marco de la intervención trinacional del proyecto. En Argentina el proyecto se implementa en el corredor verde de la Provincia de Misiones." (Anuario Araucaria XXI, 2009).

Como puede verse en este texto, el programa encarna el nuevo paradigma ambientalista: trabajar con la población local para la conservación del ambiente. En palabras de los técnicos trabajando para dicho programa, la idea es evitar la presión de los pobladores sobre las áreas naturales protegidas, creando zonas buffer o de amortiguamiento en torno a éstas, y asegurar la conexión entre estas áreas.

El Proyecto Araucaria se organiza en diversos componentes, dos de los cuales trabajan con pobladores locales: el componente de "desarrollo productivo", cuyo objetivo es apoyar emprendimientos de desarrollo entre productores colonos; y el componente "guaraní", que incentiva el desarrollo de comunidades indígenas que se encuentran cerca del Parque Nacional.

Dentro del componente de desarrollo productivo, los emprendimientos priorizados son: por un lado la cooperativa Cabureí, que se constituyó a partir de un proyecto de JICA (Japan International Cooperation Agency), donde trabaja personal de 
Parques Nacionales con una mirada afín al paradigma participativo de conservación. Dicha cooperativa consta de 15 productores, mayoritariamente tabacaleros, que viven en un paraje lindante al Parque. La idea de la cooperativa es "vender los productos de la colonia en la ciudad de Iguazú sin intermediarios". En esta zona, algunas personas se dedican a acopiador productos de la colonia de manera informal y esporádica, para venderlos en mercados de Iguazú, debido a la gran demanda que existe por los volúmenes de turistas que visitan la localidad. Cabe destacar que esta localidad, a pesar de encontrarse cercana a zonas rurales con gran cantidad de pequeños productores de alimento, es abastecida principalmente de productos provenientes de otras provincias, mientras que la escala productiva de los pequeños productores continúa siendo para el autoconsumo. Como una primera etapa esta cooperativa se basa en la producción y comercialización de productos manufacturados hechos a base de mandioca. La elección de este producto se debe a considerar que su cultivo no implica el avance sobre el monte.

Por otro lado, a través del proyecto, se buscó apoyar a emprendimientos productivos de una organización de productores rurales (Unión de Trabajadores Rurales), que venía trabajando en la zona del corredor verde desde hace aproximadamente 15 años, con la modalidad de grupos de productores convocados por técnicos de diversas instituciones estatales y ONGS. Estos grupos se constituyeron en una organización a principios de la década de 2000. El trabajo de Araucaria consiste en apoyar proyectos que ya venían siendo desarrollados, en particular de producción de cebolla, pollo campero y producción porcina, para su posterior comercialización.

Desde la implementación del componente de desarrollo productivo, se convocó a mesas de diálogo donde participaron organismos estatales y agencias no gubernamentales de conservación y desarrollo ${ }^{3}$. A través de generar alianzas con ciertos sectores de estas instituciones, se propuso sostener un nuevo modelo de intervención que considera que los colonos avanzan sobre el monte debido a estar subordinados a las empresas tabacaleras, sin capacidad de acceso a mercados de otros productos. En general las evaluaciones previas consideraban que el avance sobre la selva se debe a razones "culturales", que convierten al colono en depredador. En estos espacios de diálogo se estableció que el eje del trabajo debía ser generar mejores posibilidades de comercialización de la producción.

El proyecto Araucaria XXI llevó a una institucionalización del campo del desarrollo rural a nivel local ya que fortaleció el vínculo entre organizaciones que venían trabajando en el área de forma independiente. A su vez generó nuevos lazos con organizaciones ambientalistas, donde las acciones son consensuadas en mesas de diálogo. Vale señalar que el componente de desarrollo productivo encuentra dificultades debidas a la falta de financiamiento. En las instituciones que implementan el proyecto Araucaria las líneas internas que promueven el nuevo paradigma son minoritarias, estando subordinadas a los enfoques tradicionales.

$\overline{3}$ Las agencias son INTA, PSA, UNAM, SENASA, PNI y las ONGs FVSA y Conservación Argentina. 


\section{Institucionalización de la población}

La adquisición de un carácter ambiental de los conflictos sociales consiste en buscar institucionalizar los conflictos y los ámbitos de su resolución, considerando que sólo es posible resolverlos en ámbitos formales de diálogo que deben ser reconocidos por todos los actores. Esto implica, crear horizontes discursivos comunes sobre la conservación, el desarrollo y la población.

En tal sentido, se asiste a una nueva forma de establecer gobernabilidad en el territorio, creando privilegios y exclusiones, "puesto que las instituciones concretan espacios de discurso y de praxis, definen espacios de acción, privilegian ciertas formas de acción y limitan otras" (Santamarina; 45: 2008). De manera que las instituciones medio ambientales, lejos de ser liberadoras, son sobre todo formas de intervención (Brosius; 1999). Este proceso representa el desplazamiento político en el dominio del medio ambiente y debe ser leída como un proceso de gobernabilidad en el sentido foucaultiano.

La institucionalización en el caso de las comunidades mbya implicó un proceso donde fue posible construir un horizonte de discusión, e imponer cierta dinámica. Por un lado, fue central que las comunidades contasen con asesoramiento legal (a cargo del Equipo Nacional de la Pastoral Aborigen). En las experiencias previas la única forma de relacionarse con Estado había sido a través de sistemas clientelares con funcionarios de distintas áreas de la administración pública.

Por otro lado, el principal factor de institucionalización fue la constitución de un espacio formal para la interacción con las instituciones estatales. La modalidad organizativa que propiciaron los funcionarios de la AMIRBY, fue recuperar una antigua institución existente entre las comunidades, pero que había desaparecido hacía varias décadas. El "aty guasú" (reunión grande), es una forma de asamblea que reúne a líderes de diversas comunidades mbya-guaraní, y que se habían dejado de realizar hacía varias décadas. Se consideró que recuperando un elemento tradicional guaraní se le daba mayor vigor a la cultura mbya, a su vez que el choque con la lógica estatal se aminoraba.

A partir de 2006 se comienzan a realizar los "aty guasú" en el área de la Reserva. La AMIRBY hizo grandes esfuerzos para que se realizasen estas reuniones tradicionales, financiándolas, ofreciendo comida y comodidades durante su realización en determinadas comunidades, y recorriendo toda la Reserva informando la fecha en que se harían, luego trasladando a los líderes de las distintas comunidades al lugar de cada "aty guasú" y después llevándolos de vuelta. En estos "aty guasú" sólo participan quienes son autorizados por el conjunto de líderes mbya, en todas se ha permitido la asistencia de blancos, sólo cuando se habían conseguido acuerdos entre los líderes indígenas, de manera que no se permitió la presencia de blancos en las discusiones entre los mbya. Puesto que no está estipulado cuánto tiempo puede durar un aty guasú, los blancos (representantes de la AMIRBY, Ministerio, Áreas Protegidas, Araucaria y Universidad) debían esperar en un centro de la Universidad de Misiones, a veces varios días, hasta ser convocados para reunirse con los mbya. 
Finalmente la institucionalización quedó formalizada en una periódica consulta a los líderes mbya por parte de los funcionarios del ministerio de Ecología, AMIRBY. Las comunidades pasaron a tener un lugar permanente en el Comité de Gestión de la Reserva, donde se sientan a discutir sobre el manejo de la Reserva junto a funcionarios estatales, propietarios de tierras.

En el caso de la ocupación de tierra por parte de colonos dentro de la Reserva de Biosfera, la modalidad elegida para resolver el problema fue institucionalizarlo, creando un espacio de diálogo y participación entre diversos actores. Se les dijo a los vecinos que para poder iniciar un diálogo con el Estado debían organizarse, sugiriéndoles la forma de hacerlo conformando un grupo de vecinos que contase con una comisión directiva. De esta manera los vecinos conformaron el Grupo Esperanza. El presidente es uno de los líderes de la toma de tierras, quien justifica la creación Grupo en que "necesitamos de que si nosotros vamos a preguntar algo queremos que alguien nos responda de buena manera porque muchas veces en el país que estamos a veces eso te cansa porque si vos te vas queriendo saber algo, o decir algo de lo que está pasando no te reciben de manera, no podes seguir a ningún lado".

El diálogo con el Estado se dio en el marco de una Mesa de Diálogo creada entre el grupo Esperanza y el Estado Provincial, a través de la Subsecretaría de Ecología, AMIRBY y dependientes del Ministerio de Ecología; la Subsecretaria de Tierras y Colonización; la Comisión de Ordenamiento Territorial de la provincia. El objetivo de la mesa de Diálogo fue "lograr un exacto conocimiento de la situación social de las personas involucradas y considerar y efectuar los planteos de soluciones posibles a las demandas entre las que cabe consignas potenciales necesidades de tierras, y resunta reubicación, programas de desarrollo productivo e inclusión social"4. De esta manera se profundiza el control del área, que pasa a organizarse en los términos que propone el Estado y las organizaciones conservacionistas, y se crea una nueva institucionalidad. Esta institucionalidad es entendida como la habilidad de grupos locales para establecer reglas, arreglos y normas en torno al uso de los recursos, así como la construcción de capital social. Entendiendo capital social como el conjunto de redes, normas y confianza social que facilita la cooperación. En el caso de los regímenes de acción colectiva, se consideran tres formas de capital social: confianza y reciprocidad; redes y compromisos civiles; y reglas: instituciones formales e informales (Monterroso 2006: 241).

También en el caso del proyecto Araucaria se observa el proceso de institucionalización en tanto impulsó la articulación formal el trabajo de diversas instituciones de desarrollo rural que trabajaban individualmente, y por otro lado generó espacios grupales formalizados de toma de decisiones sobre la producción y comercialización, en torno a la creación e impulso a cooperativas agrícolas, donde aparecen nuevos actores como el Ministerio de Ecología y Parques Nacionales.

$\overline{{ }^{4} \text { En Documento } 1^{\circ}}$ Mesa de Diálogo. Citado por Palma 2008:14. 


\section{Cambio representaciones sobre la población y sobre el territorio}

La adquisición de un carácter ambiental del territorio tiene lugar junto a cambios en la forma en que son percibidos los pobladores, tanto los colonos como los mbyaguaraní. Históricamente, los colonos se presentaron como los heroicos constructores de la civilización en el interior de la provincia: quienes lucharon contra ese infierno verde que es la selva, abrieron la muralla de selva para permitir que la producción agrícola enriqueciese a la nueva Misiones. Ya hacia finales de los años '80, cuando la frontera agraria estaba terminado de ocupar las tierras fiscales con selva, y ya en los '90 cuando se fortalece la industria forestal, esta imagen de los colonos comienza a transformarse, y éstos comienzan a ser presentados en la sociedad como los destructores de la selva, quienes están produciendo la pérdida de la riqueza natural. Se multiplican en los diarios locales las noticias sobre incendios forestales que se originan en los rozados con fuego hechos por los colonos, a su vez que se hace subraya la poca colaboración de éstos para apagar los incendios. Esta imagen de los colonos sirvió para legitimar las políticas de creación de Áreas Naturales Protegidas como espacios de selva a salvo de los colonos, a su vez se asiste a enfrentamientos entre pobladores rurales y guarda parques. Ya en el siglo XXI los pobladores comienzan a ocupar otro lugar en este territorio, gradualmente comienzan a levantarse voces que señalan la necesidad de integrar a los pobladores rurales a las políticas de conservación, donde inclusive algunos se aventuran a plantear que conservación y desarrollo deben ser dos aspectos de un mismo proceso.

Durante la expansión del frente extractivo las poblaciones indígenas junto a criollos ocuparon el rol de mano de obra semi-esclava. En el proceso de incentivar el poblamiento de la provincia para el desarrollo agrícola, impulsado desde el Estado, las comunidades aborígenes que poblaban el territorio fueron invisibilidades, ya que el aborigen no se correspondía con el ideal de sujeto nacional apto para el desarrollo. La visión que se tenía sobre él era que respondía a una lógica de valores improductiva, lo que permitía su explotación como mano de obra. Con el predominio de las producciones agrícola y forestal, las poblaciones indígenas viven en general en latifundios de propiedad privada, y tierras otorgadas por el Estado provincial, en condiciones de extrema pobreza, en general ocupándose como trabajadores jornaleros, en la producción y venta de artesanías, y la producción de subsistencia. En las políticas de creación de Áreas Naturales Protegidas, las poblaciones indígenas o fueron expulsadas de las tierras que ocupaban y donde se crearon Reservas, tal el caso del Parque Provincial Cuña Pirú donde se expulsó a dos comunidades, o predominantemente fueron invisibilidades, creándose Reservas en tierras por ellos ocupadas sin que constase en las actas o leyes de creación, tal el caso de la mayor parte de los Parques Provinciales y de la Reserva de Biosfera Yabotí.

En el actual paradigma participativo de conservación, el colono y el indio se presentan como potenciales aliados para la conservación. A los colonos se los considera como poseedores de capacidades para una producción artesanal, a pequeña escala, que se opone al tipo de producción que llevan a cabo las grandes empresas forestales que 
transforman grandes extensiones de selva en monocultivos de coníferas. Mientras que a las comunidades indígenas se las valora por sus conocimientos autóctonos sobre el ambiente, y se las comienza a considerar como fuertemente "espirituales". Tal como señala un boletín del Proyecto Araucaria XXI, "la comunidad guaraní de la provincia de Misiones, al igual que la selva que los ampara, son resabios de un mundo que vivió en armonía, por comprender en su cosmovisión, una única integridad entre la vida y la muerte, entre la naturaleza y el espíritu, y por sobre toda las cosas, en el sentido de la pertenencia. La tierra no es de ellos, según su filosofía de vida, sino, que son ellos los que pertenecen a la tierra. El objetivo central de Proyecto Araucaria XXI, en particular el componente siete: contribuir a recuperar la identidad del mundo mbya guaraní". Cabe destacar que este Proyecto organiza reuniones "de recuperación de la espiritualidad guaraní", donde se consensuó con los indígenas que para la asistencia a las mismas recibirían un pago en efectivo.

Otra nueva representación que se construye sobre indios y colonos está dada en considerarlos como "pobladores locales". Esta noción alude a quienes habitan las áreas sobre las que se despliega el nuevo paradigma. El término "local" se presenta como una referencia universal ya que alude a lugares indiferenciados: cada rincón del planeta es un lugar local. La identidad que adquieren los "pobladores locales" se define por oposición a lo "global". A cada actor se le asigna un campo de acción, las agencias transnacionales, nacionales, provinciales, los Estados, son actores "globales". A su vez, a cada tipo de actor se le asignan responsabilidades ligadas a su campo de acción, los globales planificando proyectos y políticas a implementar a diversos niveles, de eco región, ecosistema, nación, provincia, mientras los "locales" tienen responsabilidades de ser los ejecutores en campo de tales políticas y proyectos. Queda en evidencia la diferencia en capacidades de acción y poder entre unos y otros, lo cual trata de ser saldado por los que piensan a nivel "global" dándoles poder, o empoderándolos (término caro a este discurso ambientalista). Pero éste es un poder restringido.

La definición de "actores locales" por otro lado, se restringe a un determinado tipo de pobladores y productores. Entre los agentes ambientalistas tal concepto no refiere las empresas forestales, ni siquiera a las empresas chicas, que no son cuestionadas en las lógicas que determinan su accionar sobre el ambiente, por representar una de las principales pilares de la economía regional, siendo aceptada su búsqueda de maximización de intereses.

"Si observamos el tipo de gobernabilidad establecida como una función de las relaciones de poder por la cual una cierta constelación de instituciones participativas son creadas, vemos que estamos trabajando con problemas de poder, y problemas de ideología que legitiman esas acciones. Esas ideologías, con sus discursos y narrativas, son usadas estratégicamente por actores para estructurar su gobierno y las instituciones para su propio beneficio". (Galvin \& Haller; 2008:32)

A nivel de las representaciones sobre el territorio, el nuevo paradigma también implica nuevas formas de pensarlo. Durante la ocupación agrícola del espacio misionero, 
se consideró a la selva como un freno al progreso, una barrera verde cuya expansión era necesario combatir para convertirla en agrícola. Con la nueva mirada ambientalista, la provincia de Misiones comienza a valorarse por ser uno de los últimos espacios con selva, el territorio misionero se presenta como parte del ambiente global, y como un componente fundamental, pasa a ser un "pulmón del planeta". La selva aparece como un ambiente global a ser gestionado, cuidado, de éste depende el bienestar del mundo. De manera que los "pobladores locales" adquieren una responsabilidad extra de ser "guardianes de la selva".

\section{Consideraciones finales}

En el contexto del nuevo paradigma participativo de conservación, el ambientalismo se está tornando un campo desde donde se construye territorialidad, que conlleva una nueva forma de institucionalizar el territorio y manejarlo tanto por parte del Estado, como por agencias no gubernamentales ambientalistas y de desarrollo. En tal proceso, el ambientalismo se presenta como un medio eficaz de resolver conflictos sociales y territoriales. Aquí, es central el despliegue de un aparato institucional ambientalista que implica la presencia de nuevos actores, proyectos y discursos, y la redefinición de los que ya se encontraban presentes.

En este sentido, los pobladores locales pasan a ocupar posiciones redefinidas frente al Estado y las agencias de desarrollo y conservación: las comunidades aborígenes pasan a ser vistas como parte de la selva a conservar, en lugar de actores improductivos en los procesos de desarrollo. Los colonos pasan a ser vistos como potenciales conservadores de la selva debido a que pueden producir de una forma "tradicional", en lugar de depredadores irracionales. También, el proceso que llevó a la ocupación del territorio durante el siglo XX, pasa a ser visto como una forma de depredación de la selva, en lugar de avance de un frente agrícola. De manera que muchas poblaciones comienzan a ser integradas a la creación de territorios ambientalistas mediante procesos de institucionalización particulares, para poner un freno a la depredación.

La institucionalización del territorio se da creando mesas de diálogo, otorgándole voz y cuotas de poder a las pobladores locales, y estableciendo redes entre organizaciones sociales que ya venían trabajando en el área, tal el caso del Proyecto Araucaria XXI. Estas formas de institucionalización propias del paradigma participativo no necesariamente traen consigo una toma de poder real por parte de estas poblaciones, sino que puede implicar nuevas formas de sometimiento, detrás de prácticas que aparentan empoderar.

En la región que analizamos, la participación de las poblaciones locales tiene lugar a partir de que estallan conflictos cuyo principal motivo la propiedad y derechos sobre la tierra, y no cuando las instituciones gubernamentales y agencias ambientalistas, cándidamente consideran que es necesario integrar a la gente. En casos aquí presentados, tales conflictos se vinculan con la ocupación de tierras privadas en la Colonia Primavera, los derechos sobre la tierra y los recursos entre comunidades mbya guaraní, y finalmente 
por transformar las condiciones de producción y comercialización de los productos, en el caso de Araucaria XXI. Es decir que la nueva forma de gobernabilidad implica redefinir el territorio y los actores vinculados a éste, propiciando la participación pero restringiéndoles el horizonte de posibilidades de acción y de autodefinición.

El cambio hacia el paradigma de la participación por si sólo muestra no ser suficiente para un manejo efectivo en el manejo de las Áreas Protegidas. Lo que cuenta es el contexto político y económico en el cual cada una de estos paradigmas tiene lugar. Si los incentivos económicos para esta clase acciones colectivas no es considerada o no se basa en la comprensión del cálculo para los responsables locales y la evaluación de su poder, intereses, necesidades y cultura, la participación sólo existe de manera retórica y en el papel.

\section{Referencias Bibliográficas}

Brosius, J. Paul. 1999. "Engagements with environmentalism". En Current Anthropology. Chicago Journals, Chicago, vol. 40, $\mathrm{n}^{\circ} 3$.

Di Bitetti, Mario, et. al. 2003. Una Visión de Biodiversidad para la Eco región del Bosque Atlántico del Alto Paraná: Diseño de un Paisaje para la Conservación de la Biodiversidad y prioridades para las acciones de conservación. Edición de World Wildlife Fund, Washington D.C.

Ferrero, Brián. 2007. La selva en Disputa. Superposición de cosmografías agraria y ambientalista en la provincia de Misiones. Tesis de Doctorado en Antropología Social. Universidad Nacional de Misiones. Posadas. Inédito.

Foucault, Michel. 1991. "La gubernamentalidad”. En Espacios de poder. Piqueta, Madrid.

Foucault, Michel. 1988. “El sujeto y el poder”. En Michel Foucault: Más allá del estructuralismo y la hermenéutica. UNAM, México.

Galvin Max y T. Haller (eds). 2008. "People, Protected Areas and Global Change: Participatory Conservation in Latin America, Africa, Asia and Europe". Perspectives of the Swiss National Centre of Competence in Research (NCCR) North-South, University of Bern, Vol. 3. Bern: Geographica Bernensia, $560 \mathrm{pp}$.

Monterroso, Iliana. 2006. "Comunidades locales en áreas protegidas: reflexiones sobre las políticas de conservación en la Reserva de Biosfera Maya". En Héctor Alimonda (Comp.) Los tormentos de la materia. CLACSO, Buenos Aires.

Murillo, Susana. 2008. Colonizar el dolor. La interpelación ideológica del Banco Mundial en América Latina. El caso argentino desde Blumberg a Cromañón. CLACSO, Buenos Aires.

Neuman, RP. 1998. Imposing Wilderness: Struggles over Livelihood and Nature Preservation in Africa. CA: University of California Press, Berkeley.

Palma, Mariana. 2008. Importancia de la gestión en el rol del guarda parque para la resolución de conflictos en el áreas naturales protegidas. Estudio del caso "Intrusión en la Reserva de Biosfera Yabotí, por campesinos de Colonia Primavera". Trabajo Final Carrera de Técnico Universitario Guarda parque. Universidad Nacional de Misiones. Facultad de 
Folia Histórica del Nordeste, $\mathbf{N}^{\circ} 19$ (Resistencia, 2011) IIGHI, IH - CONICET, UNNE

Ciencias Forestales. San Pedro. Inédito.

Schiavoni, Gabriela. 1996. Colonos y ocupantes. Editorial Universitaria UNaM, Posadas.

Santamarina Campos, Beatriz. 2008. “Antropología y medio ambiente. Revisión de una tradición y nuevas perspectivas de análisis en la problemática ecológica”. En Revista de Antropología Iberoamericana. Antropólogos Iberoamericanos en Red, Madrid, Vol. 3, Número 2.Pp. 144-184.

Wolf, Erik. 1990. "Facing Power. Old Insights, New Questions”. En: American Anthropologist. Vol 92, N 3, pp 586-596. 